\title{
Prophylactic Tobramycin Drops After Tympanostomy Tube Placement
}

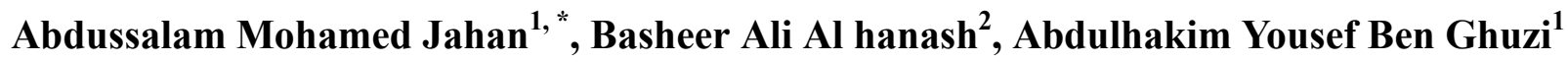 \\ ${ }^{1}$ Department of Otorhinolaryngology, Misrata Central Hospital, Misrata, Libya \\ ${ }^{2}$ Department of Otorhinolaryngology, Iben Sina Hospital, Sirt, Libya
}

Email address:

drgahan@yahoo.com (A. M. Jahan)

${ }^{*}$ Corresponding author

\section{To cite this article:}

Abdussalam Mohamed Jahan, Basheer Ali Al hanash, Abdulhakim Yousef Ben Ghuzi. Prophylactic Tobramycin Drops After Tympanostomy Tube Placement. International Journal of Otorhinolaryngology. Vol. 4, No. 1, 2018, pp. 6-10. doi: 10.11648/j.ijo.20180401.12

Received: January 8, 2018; Accepted: January 20, 2018; Published: February 21, 2018

\begin{abstract}
Tympanostomy tube insertion remains one of the most commonly performed surgeries in ENT practice. Postoperative infections remain one of the common complications after surgeries. Topical antibiotic ear drops are used to reduce the risk of this complication. The aim of this study was to assess the role of antibiotic ear drops (Tobramycin) in prevention of post-operative infection. A randomized controlled trial was done on 84 patients complaining of bilateral secretory otitis media, were operated using ventilation tube insertion. All patients were randomly allocated into two groups. The first group (group A) was the intervention group, in which all patients were given local tobramycin ear drops for five days post operatively to decrease otorrhea. The other group (group B) was the control group and no ear drops were prescribed post operatively. All patients in both groups were followed up to 14 days post operatively. A statistically significant decrease was observed in the incidence of post tympanostomy otorrhea and infections between the treatment group (group $\mathrm{A}=7.1 \%$ ), and the control group (group $\mathrm{B}=14.2 \%)(P<0.05)$. To conclude, antibiotic ear drops should be prescribed to all patients who are undergoing tympanostomy tube insertion. A 5-day course post operatively with tobramycin local drops is recommended.
\end{abstract}

Keywords: Tympanostomy Tube, Secondary Infection, Antibiotic Ear Drop

\section{Introduction}

Insertion of tympanostomy tubes is one of the most common surgical procedures performed on children worldwide. The tympanostomy tube, which is approximately $1 / 20^{\text {th }}$ of an inch in width, is placed in the child's eardrum (tympanic membrane) to ventilate the middle ear space [1], [2]. Tympanostomy tubes are most often inserted because of persistent middle ear fluid, frequent ear infections, or ear infections that persist after antibiotic therapy. All of these conditions are encompassed by the term otitis media (middle ear inflammation) [3].

Children younger than 7 years of age are at increased risk of otitis media, because of their immature immune systems and poor function of the Eustachian tube. The Eustachian tube a slender connection between the middle ear and back of the nose that normally ventilates the middle ear space and equalizes pressure with the external environment [4]. When children require surgery for otitis media with effusion (OME), insertion of tympanostomy tubes is the preferred initial procedure, with candidacy dependent primarily on hearing status, associated symptoms, and the child's developmental risk [5], [6].

Placement of tympanostomy tubes significantly improves hearing, reduces effusion prevalence [5], [6], may reduce the incidence of recurrent acute otitis media (AOM), and provides a mechanism for drainage and administration of topical antibiotic therapy for persistent AOM. In addition, research indicates that tympanostomy tubes also can improve disease-specific quality of life (QOL) for children with chronic OME, recurrent AOM, or both [7]-[9]. Risks and potential adverse events of tympanostomy tube insertion are related to general anesthesia, which is usually required for the procedure, and the effect of the tympanostomy tube on the tympanic membrane and the middle ear [10]. This prospective clinical study aims to assess the role of topical antibiotic eardrops (tobramycin) on post-operative results 
regarding the infection after surgical insertion of a ventilation tube.

\section{Methods}

This study was conducted as prospective, randomized, double blind clinical trial on 84 patients aged 2-15 years old, attending the ENT department of Zahrawi hospital, Misrata (Libya). The indication of ventilation tube insertion is secretory otitis media. Exclusion criteria include patient with associated surgical intervention, such as adenoidectomy or tonsillectomy, and any patient with systemic disease.

Patients were informed about the study protocol prior to initiation of recruitment, and a written, informed statement consent were obtained from all participating patients (or child's parents). All patients were blinded as to which group they belong. A total of 84 patients who signed a consent and agreed to participate in this study were allocated into 2 groups (Group A, and Group B). Each group includes 42 patients.

In group A (the intervention arm), all patients discharged on analgesia (paracetamol) and local ear drops (tobramycin), while in group B (the control arm), patients were discharged post operatively on analgesia only. As a preparation to surgery, all candidates were requested to come at 8 am sharp on the scheduled day of the operation fasting for at least 8 hours. All operative procedures were performed under general anesthesia using endotracheal intubation.

An operating microscope with a $250-\mathrm{mm}$ lens is brought into the field and focused on the external auditory meatus. An oval 4-mm speculum (e.g., Gruber type, of a size appropriate for visualizing the tympanic membrane) is placed into the external auditory canal, and the cerumen is removed so that the entire tympanic membrane can be visualized. The anterior half of the eardrum is then visualized with the tympanic annulus anterior and the umbo posterior. A horizontal incision is placed over the region of the middle ear, most commonly in the anteroinferior quadrant. It should be deep enough to incise the eardrum but not so deep that it injures the middle structures. The incision may have to be slightly smaller than the diameter of the tube's inner flange. The knife incising all layers of the eardrum should be placed in the center of the field of vision to leave sufficient room for visualizing the insertion of the tube.

If an effusion is present, a 3, 5 or 7 French Baron suction cannula, with or without saline irrigation via an angiographic catheter, is employed. Large (7 French) suction cannulas are essential for removing the thick inspissated fluid that is frequently present in chronic otitis media with effusion (OME). A Shabred grommet tube is introduced by holding the posterior surface of the inner flange with small alligator forceps. The tube is then passed through the speculum to the anterior-inferior canal; the anterior surface of the flange is inserted into the drum. If necessary, insertion is completed with a curved or straight pick. Most tubes can be inserted directly with small alligator forceps. Residual effusion or blood is aspirated. All patients in both groups underwent a regular follow ups in $3^{\text {rd }}, 7^{\text {th }}$, and $14^{\text {th }}$ days post operatively, to check if there is any discharge or otorrhea.

\section{Results}

A total of 84 patients were operated for bilateral secretory otitis media. Their age ranged from 2-15 years, with mean age of 5 years. There were $46(54.8 \%)$ females and 38 (45.2\%) males (fig. 1). All patients underwent bilateral tympanostomy tube placement under general anesthesia. Regular post-operative follow ups were done to assess the patients regarding otorrhea or infections.

In group A (the intervention group), only 3 cases (7.1\%) developed otorrhea postoperatively (see Table 2 ). In group B (the control group), where no local drops were prescribed, 6 cases $(14.2 \%)$ had developed post-operative otorrhea (see table 3).

Table 1. Gender distribution in both the intervention and the control groups.

\begin{tabular}{llll}
\hline 1 & Female & 46 & $54.80 \%$ \\
2 & male & 38 & $45.20 \%$ \\
\hline
\end{tabular}

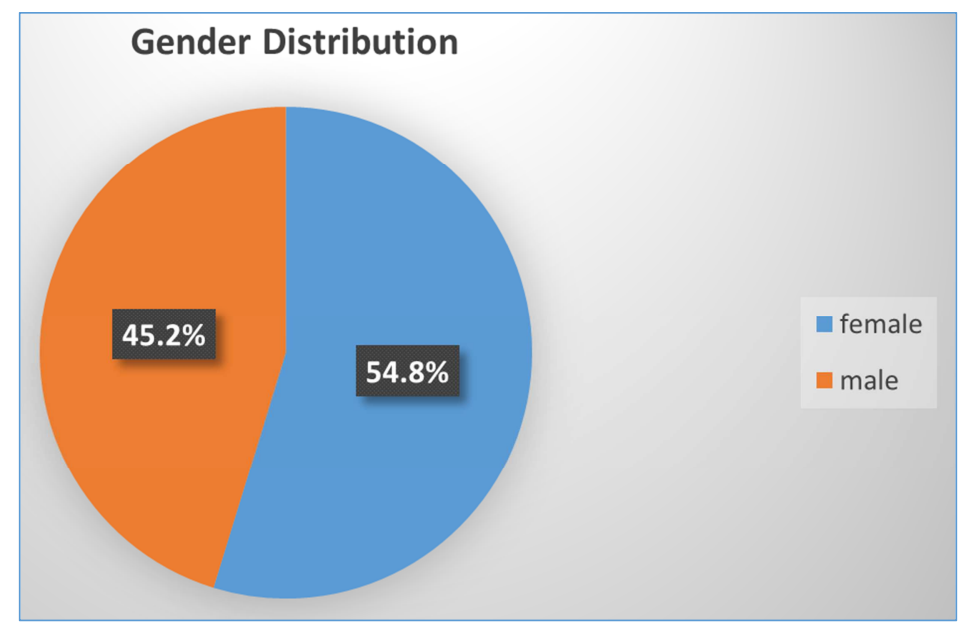

Figure 1. Gender distribution in the study. 
Table 2. Group A (the intervention group).

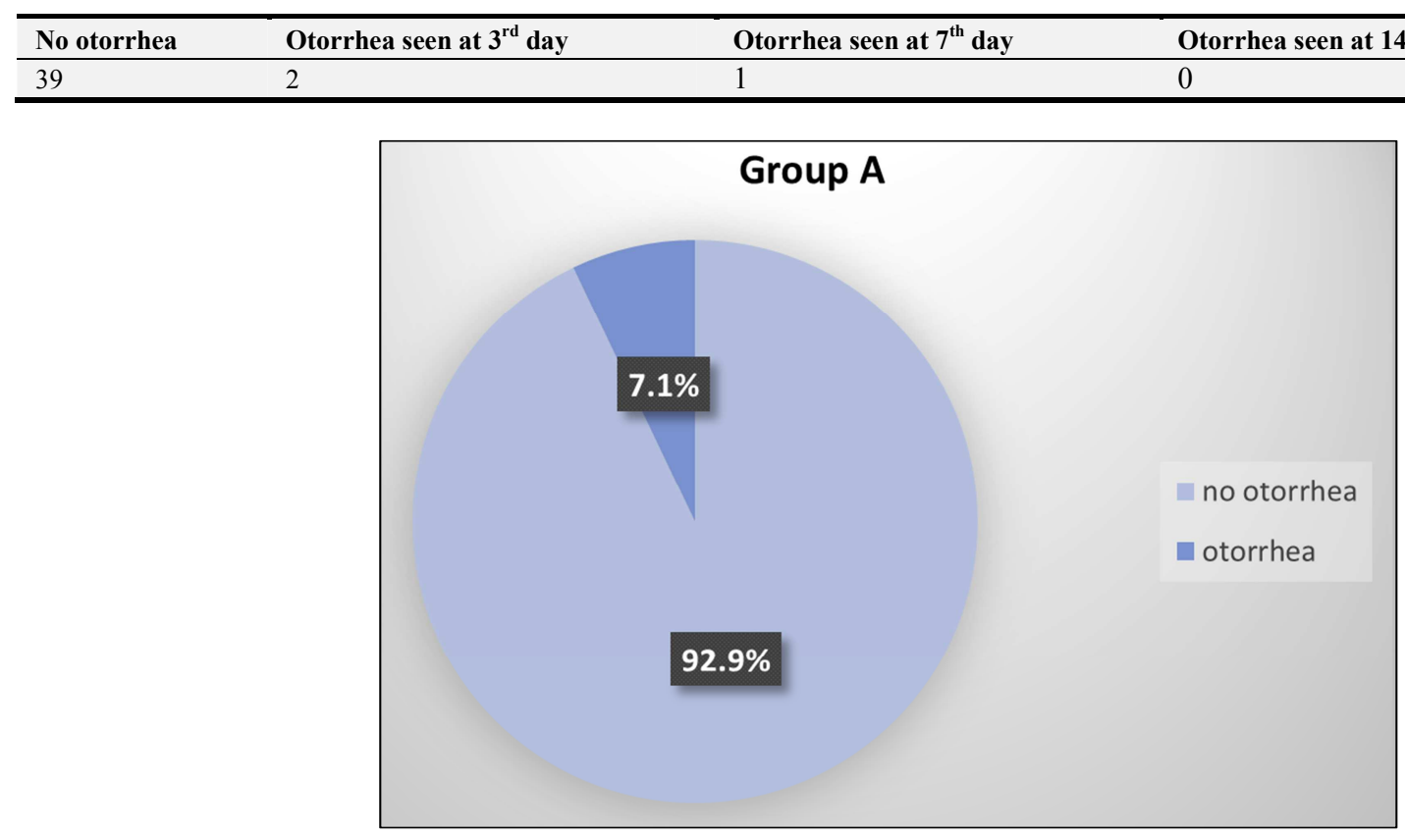

Figure 2. Patients' distribution in the intervention group postoperatively.

Table 3. Group B (the control group).

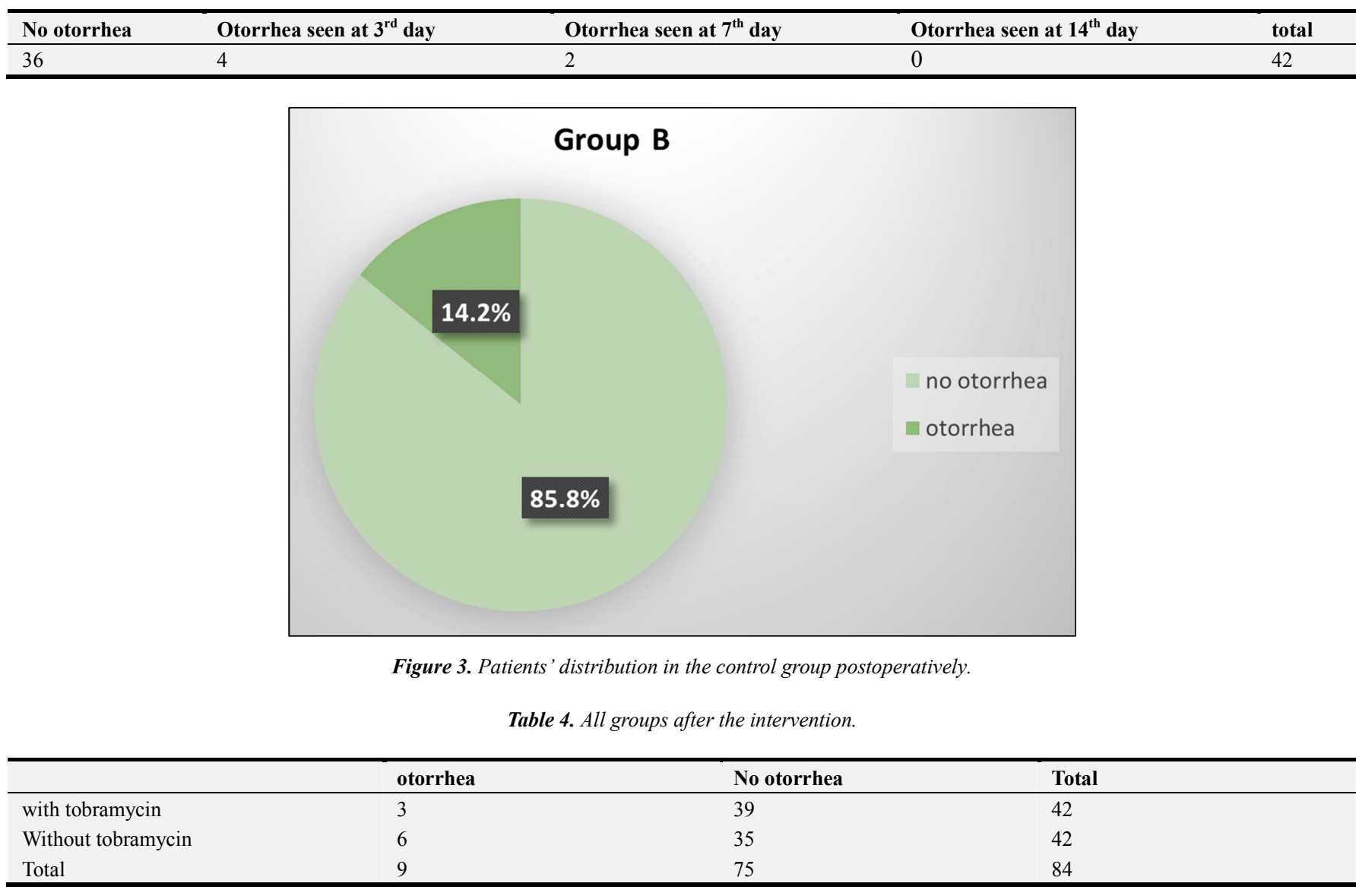




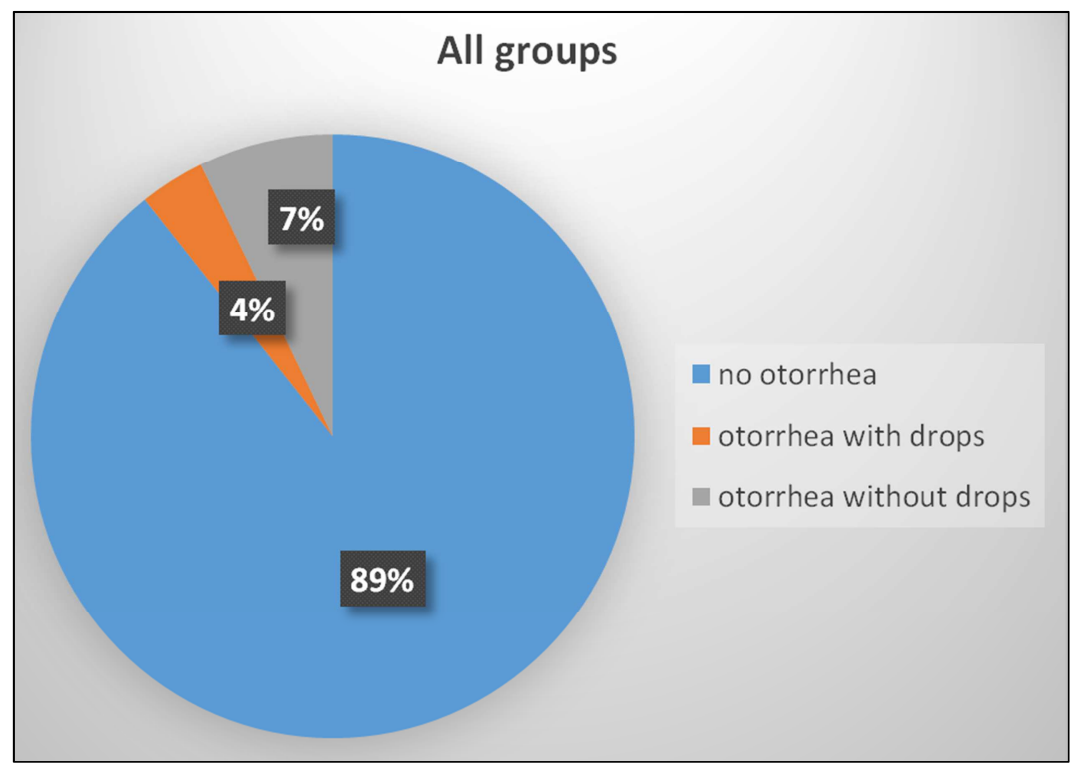

Figure 4. Patients' distribution in all groups.

\section{Discussion}

Ventilation tube insertion is one of the most common procedures for otitis media with effusion [11], [12]. It serves as artificial Eustachian tubes, thereby equalizing the middle ear pressure and allowing fluid drainage [13], [14]. In the current study, the using of post-operative local drops has decreased the incidence of post-operative otorrhea to only $7.1 \%$ of patients. While $14.2 \%$ of participants in the control group have developed otorrhea. The findings of this study were comparable to Hester's et al. study, in which they reported the incidence of otorrhea in control group was $16.4 \%$ and among group using antibiotic was $8.3 \%$ [15].

Elden and Marsh in their survey study found that $80 \%$ of respondents used eardrops at the time of surgery. It was estimated that $11 \%$ of respondents applied eardrops only when discharge was present, and only $7 \%$ of them had used the drops when thick mucus or blood was observed. About $2 \%$ of respondents have never applied eardrops. The most commonly used drops contained antibiotic alone $(56 \%)$ or a combination of antibiotic and steroids (35\%). Approximately $13 \%$ of study participants applied decongestant drops containing oxymetazoline or xylometazoline. Nearly all (94\%) of physicians instructed their patients to use eardrops postoperatively from 2 to 3 times per day for a period of 2-7 days [12].

Ramadan et al. conducted a 1-year prospective study on 60 patients with chronic serous otitis media who had bilateral tympanocentesis with tube insertion. The right ear was treated intra-operatively with dexapolyspectran (a solution contains polymyxin B sulfate, neomycin sulfate, sulfonamide and hydrocortisone). Five (8.3\%) out of 60 experimental ears had purulent otorrhea within the first 14 days after surgery, compared with eight (13.3\%) out of 60 control ears. Statistical analysis showed no significant difference between the two groups [16].

\section{Conclusion}

Tympanostomy tube insertion remains one of the most commonly performed surgeries in ENT practice. Postoperative infection is one of the common complications after surgery. Topical antibiotic ear drops are usually prescribed to reduce the risk of this complication. The findings of the current study revealed that using local eardrops, such as Tobramycin, post operatively in tympanostomy surgery is effective and safe to decrease the incidence of post-operative infections and otorrhea.

\section{References}

[1] Kogan MD, Overpeck MD, Hoffman HJ, et al. Factors associated with tympanostomy tube insertion among preschool-aged children in the United States. Am. J. Public Health. 2000; 90:245-250.

[2] Steele DW, Adam GP, Di M, et al. Effectiveness of Tympanostomy Tubes for Otitis Media: A Meta-analysis. Pediatrics. 2017; 139.

[3] Centers for Disease Control and Prevention. Table 2: top 5 diagnoses at visits to office-based physicians and hospital outpatient departments by patient age and sex: United States 2008. Atlanta, GA: Centers for Disease Control and Prevention; 2008.

[4] Bluestone CD, Swarts JD. Human evolutionary history: consequences for the pathogenesis of otitis media. Otolaryngol.--Head Neck Surg. Off. J. Am. Acad. Otolaryngol.-Head Neck Surg. 2010; 143:739-744.

[5] Rosenfeld RM, Culpepper L, Doyle KJ, et al. Clinical practice guideline: Otitis media with effusion. Otolaryngol.--Head Neck Surg. Off. J. Am. Acad. Otolaryngol.-Head Neck Surg. 2004; 130:S95-118. 
[6] Rosenfeld RM, Shin JJ, Schwartz SR, et al. Clinical Practice Guideline: Otitis Media with Effusion (Update). Otolaryngol.-Head Neck Surg. Off. J. Am. Acad. Otolaryngol.-Head Neck Surg. 2016; 154:S1-S41.

[7] Browning GG, Rovers MM, Williamson I, et al. Grommets (ventilation tubes) for hearing loss associated with otitis media with effusion in children. Cochrane Database Syst. Rev. [Internet]. John Wiley \& Sons, Ltd; 2010.

[8] Lous J, Ryborg CT, Thomsen JL. A systematic review of the effect of tympanostomy tubes in children with recurrent acute otitis media. Int. J. Pediatr. Otorhinolaryngol. 2011; 75:10581061 .

[9] Rosenfeld RM, Bhaya MH, Bower CM, et al. Impact of tympanostomy tubes on child quality of life. Arch. Otolaryngol. Head Neck Surg. 2000; 126:585-592.

[10] Kay DJ, Nelson M, Rosenfeld RM. Meta-Analysis of Tympanostomy Tube Sequelae. Otolaryngol.-Head Neck Surg. 2001; 124:374-380.

[11] Badalyan V, Schwartz RH, Scwhartz SL, et al. Draining ears and tympanostomy tubes: a survey of pediatric otolaryngologists and pediatric emergency medicine physicians. Pediatr. Emerg. Care. 2013; 29:203-208.

[12] Elden LM, Marsh RR. Survey of pediatric otolaryngologists: clinical practice trends used to prevent and treat blocked ventilation ear tubes in children. Int. J. Pediatr. Otorhinolaryngol. 2006; 70:1533-1538.

[13] Altman JS, Haupert MS, Hamaker RA, et al. Phenylephrine and the prevention of postoperative tympanostomy tube obstruction. Arch. Otolaryngol. Head Neck Surg. 1998; 124:1233-1236.

[14] Shishehgar M, Rahmanian AM. Phenylephrine and the prevention of post operative tympanostomy tube obstruction. 2004; 16:40-47.

[15] Hester TO, Jones RO, Archer SM, et al. Prophylactic antibiotic drops after tympanostomy tube placement. Arch. Otolaryngol. Head Neck Surg. 1995; 121:445-448.

[16] Ramadan HH, Tarazi T, Zaytoun GM. Use of prophylactic otic drops after tympanostomy tube insertion. Arch. Otolaryngol. Head Neck Surg. 1991; 117:537. 